\title{
Centralized control of parallel connected power conditioning system in electric vehicle charge-discharge and storage integration station
}

\author{
Jiuqing CAI, Changsong CHEN ( $\bowtie)$, \\ Peng LIU, Shanxu DUAN
}

\begin{abstract}
This study presents a centralized control scheme that coordinates parallel operations of power conditioning system (PCS) for the grid interactions of electric vehicles (EVs) in EV charge-discharge and storage integration station. Key issues for the control and operation of PCS under various operation modes are discussed, including vehicle to grid (V2G) mode, stand-alone mode and seamless transfer mode. The intelligent multi-mode charge-discharge method is utilized for the $\mathrm{V} 2 \mathrm{G}$ mode, and the parallel control method based on communication network is adopted for the standalone mode. In addition, a novel seamless transfer strategy is proposed, which is able to implement PCS transition between $\mathrm{V} 2 \mathrm{G}$ mode and stand-alone mode. The detailed process of the seamless transfer between the two modes is illustrated. Experimental results are presented to show the performance and feasibility of this strategy.
\end{abstract}

Keywords Centralized control, Power conditioning system (PCS), Charge-discharge and storage integration station, Vehicle to grid (V2G), Seamless transfer

\section{Introduction}

The needs to reduce pollutant gas emissions and the increasing energy consumption have led to an increase of the

CrossCheck Date: 31 March 2014

Received: 15 November 2014 / Accepted: 1 April 2015/Published online: 7 May 2015

(C) The Author(s) 2015. This article is published with open access at Springerlink.com

J. CAI, C. CHEN, P. LIU, S. DUAN, State Key Laboratory of Advanced Electromagnetic Engineering and Technology, School of Electrical and Electronic Engineering, Huazhong University of Science and Technology, Wuhan, China

$(\bowtie)$ e-mail: ccsfm@163.com electric vehicles (EVs) and renewable energy generation [1-4]. Large-scale utilization of EVs has the potential to reduce greenhouse gases emission, save fuel cost for EV drivers, enhance power system security, and increase penetration of renewable energy [5-7]. The development of the microgrid concept endows distribution networks with increased reliability and resilience and offers an adequate management and control solution for massive deployment of renewable energy generation and EVs [8-10]. EVs are considered as both a new type of load and flexible generation resources with vehicle-togrid (V2G) technology.

The charge-discharge and storage integration station, consisting of bi-directional converters and hierarchical control structure, is able to realize bidirectional power flow between EVs and power grid. Many research works on designing the topologies and controllers of bi-directional power electronic converters for EV application, which are able to function as battery charger and to transfer electrical energy between battery pack and the grid [11-13]. In addition, the centralized control system for parallel operation of the converters during grid-connected and stand-alone operations has been conducted [14-16]. The issue of seamless transition between the $\mathrm{V} 2 \mathrm{G}$ mode and stand-alone mode is discussed widely. A phase locked loop (PLL)based seamless transfer control method between grid-connected and islanding modes is applied in a three-phase grid-connected inverter [17]. The performance of the transfer process is highly dependent on the characterization of PLL. In [18], a control strategy based on the frequency and magnitude droop control is used for the distributed generation (DG) to achieve a seamless transfer between grid-tied mode and islanding mode. However, both the magnitude and the frequency of the output voltage are varied due to the droop operation. In [19], a transfer strategy based on indirect current control is proposed for the three-phase inverter in the DG. However, it is difficult 
to realize the current limiting control because the inductance current is not controlled in both operation modes. In [20], a transfer methodology is presented for the threephase grid-tied inverter without static transfer switch. In this case, because the instantaneous grid current is not introduced in the control algorithm, the harmonic performance of the grid current may not be good. Compared with the existing strategies for the grid-connected inverters [1720], the contribution of this paper on the mode transfer strategy can be concluded into two points. First, an improved transfer control strategy based on indirect current control is proposed according to the model of three-phase (power conditioning system) PCS in the synchronous reference frame. In the seamless transfer mode, double closed-loop control technology is applied, the outer loops track instructions mutually while the inner loop remains the same. Second, particular issues of bidirectional converter are considered, including the charging state and discharging state during seamless transfer between V2G mode and stand-alone mode.

In this paper, a flexible and efficient centralized control scheme is developed for the parallel connected PCS in EV charge-discharge and storage integration station. The system configuration and theoretical analysis of three operation modes principles are described. Moreover, a novel seamless transfer method of PCS between V2G and stand-alone modes is presented. Finally, the control scheme has been verified on a 1 MW parallel connected PCS prototype.

\section{System configuration}

Figure 1 shows the infrastructure of EV charge-discharge and storage integration station with parallel

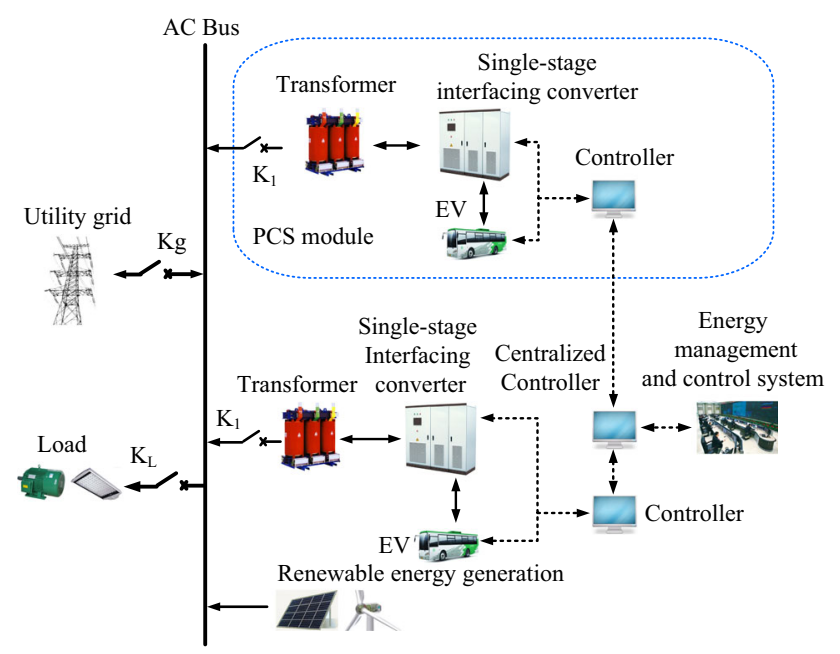

Fig. 1 Infrastructure of EV charge-discharge and storage integration station connected PCS adopting centralized control architecture. In the V2G mode, integration station is connected to the utility grid. PCS can achieve several major functions: battery charger, active power regulation and reactive power compensation. In the stand-alone mode, integration station is separated from the utility grid. PCS functions as an uninterruptible power supply (UPS) to maintain the output voltage of the integration station. The PCS should transfer between the two modes in order to provide electrical power to the critical load during utility grid interruptions.

The topology of parallel connected PCS for EV chargedischarge and storage integration station is shown in Fig. 2, where $V_{b a t}$ is the battery voltage, $L_{d c}$ and $C_{d c}$ are the dclink filter inductor and capacitor, $L_{1}, L_{2}$ and $L$ are the ac filter inductors, and $C$ is the ac filter capacitor. The $\mathrm{dc}$ power acquired by the battery packs is converted to threephase ac power through two parallel connected IGBT fullbridge with a LCL filter. Compared with the L or LC filter, LCL filter is more suitable in high-power low-switchingfrequency grid connected inverter applications due to its better performance on inhibiting grid current harmonics. Power transformer is selected to implement electrical isolation and voltage matching between battery packs and utility grid.

A three-level architecture is designed where complex control tasks are decomposed into simpler and manageable ones. The architecture consists of three levels, namely, level 1 converter control, level 2 centralized control and level 3 energy management system (EMS). The EMS is the highest level which ensures power balance within the EV charge-discharge and storage integration station. The centralized system as the middle level is responsible for coordinating the parallel operation of PCSs. The centralized control center uploads parallel system operation status and obtains the dispatch order from EMS through serial communication interface. The converter controller is the lowest level which handles the primary control of PCS. The converter controller sends the voltage-current instruction and receives the synchronization signal and operation mode instructions from centralized control center by optical fiber cable and controller area network (CAN) respectively.

\section{Operational modes and control strategy}

\subsection{V2G mode}

As shown in Fig. 3 the double-loop control uses the grid current loop to generate the reference for the inverter current loop under dq synchronous rotating coordinate. During the discharging process of Li-ion battery packs, PCS modules work as grid-connected inverters, the 


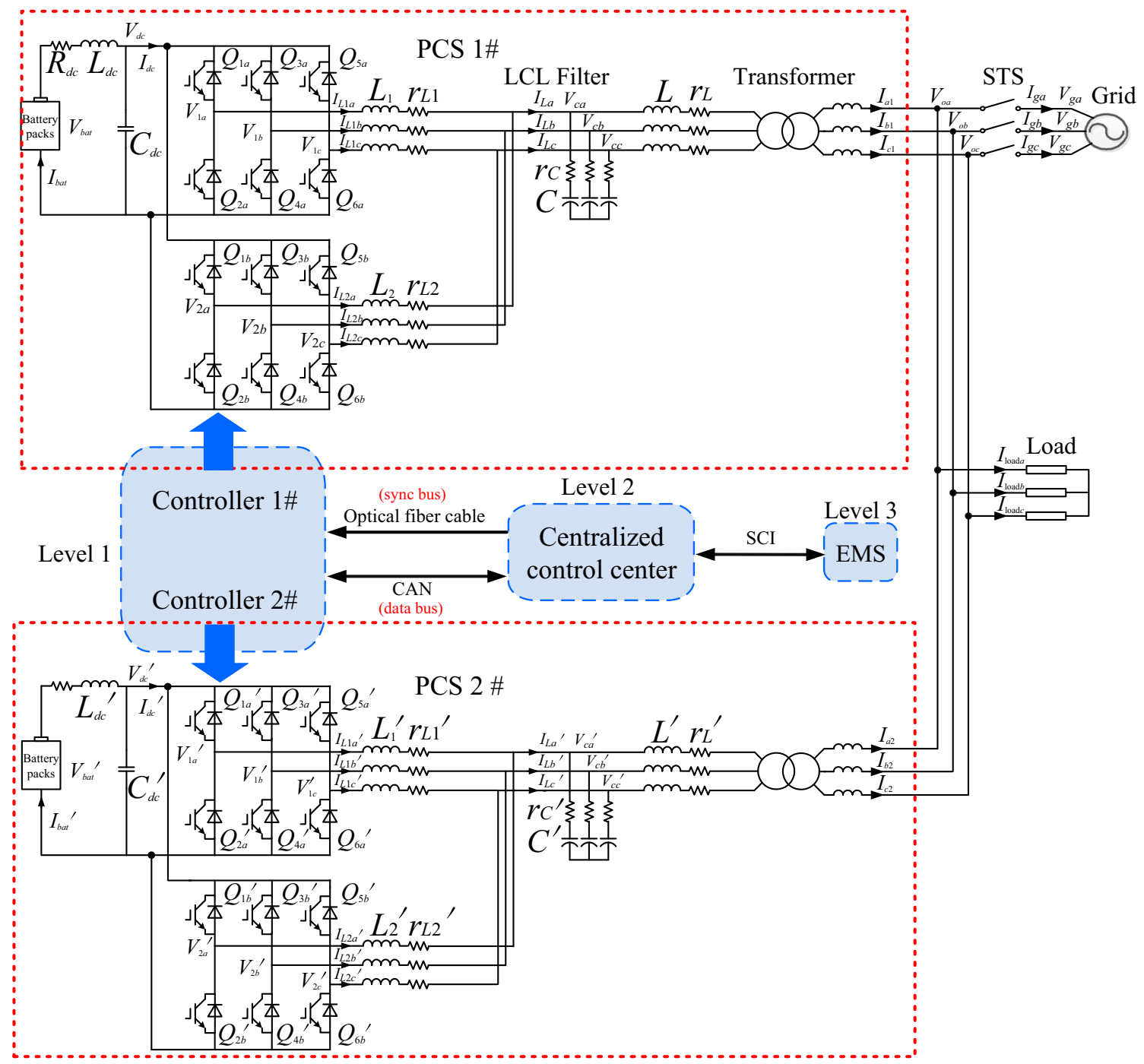

Fig. 2 Topology of parallel connected PCS

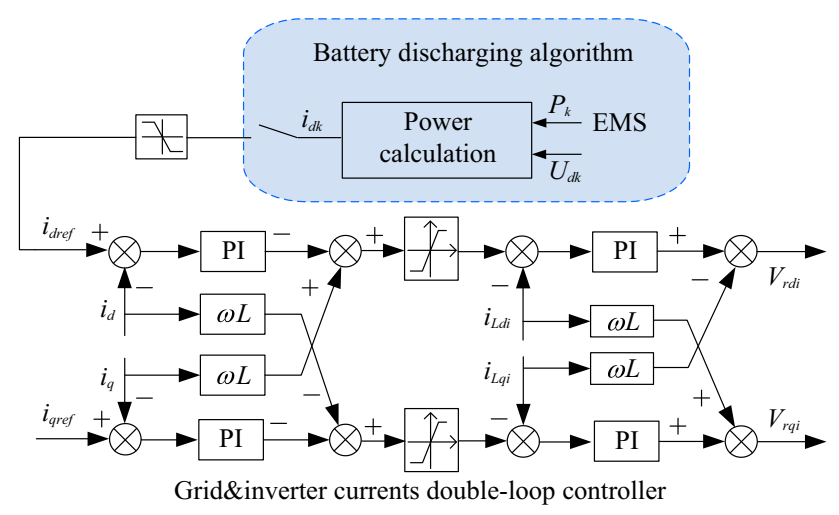

Fig. 3 Controller block of discharging in V2G mode

discharging power is determined by the EMS. The bi-directional converter will control the active-reactive power and insure the output current harmonics to be low.
During the charging process of Li-ion battery packs, PCS modules work as grid-connected rectifiers. The bidirectional converter will control the power factor to unity and insure the input current harmonics to be low. In addition to the double-loop controller above, external controllers are designed to regulate the battery current and battery voltage respectively as shown in Fig. 4. Considering the battery state and application requirement under various conditions, the battery charging algorithm should be flexibly selected.

Constant current-constant voltage $(\mathrm{CC}-\mathrm{CV})$ charging method is adopted as conventional charging method. Under the arrangement of $\mathrm{CC}-\mathrm{CV}$ charging algorithm, a constant current are applied to charge the battery till the transition time from $\mathrm{CC}$ to $\mathrm{CV}$ determined by terminal voltage of the battery. Then constant voltage is held after reaching the terminal voltage and the charging current will reduce automatically. Finally, the battery packs are fully charged. 
This charge strategy can effectively increase the battery life cycle and avoid overcharge.

However, a faster and more efficient charging algorithm is required. The pulse charge with constant voltage (CVPC) charging method is adopted as advanced charging method. The basic idea of the CV-PC is to adjust the duty cycle of the pulse within a certain range and obverse the response of the charging current. This charge strategy can really retard the polarization and reduce the batterycharging time.

\subsection{Stand-alone mode}

The block diagram of double-loop control in the standalone mode is described in Fig. 5.

The capacitor voltage loop generates the reference for the inverter current loop under $\mathrm{dq}$ synchronous rotating coordinate. PCS module works as voltage source converter, the output voltage should keep strictly sinusoidal. When PCS modules are connected in parallel, circulating currents will inevitably occur due to the asynchronous switching process and module parameter difference. In order to effectively solve the impact of circulating current and to achieve superior accuracy of current sharing, the powersharing controller is designed besides the double-loop controller.

Due to the voltage source nature, each PCS module has to be strictly consistent in output voltage amplitude, frequency and phase to suppress the circulating current. Synchronization is essential to achieve reliable parallel operation, which can be solved by a synchronization bus through the optical fiber cable. Rapid transmission rate of optical fiber can ensure the minimal synchronous error. The introduced power sharing strategy depends on the activereactive power and output impedance of PCS module. The data exchange between centralized controller and converter

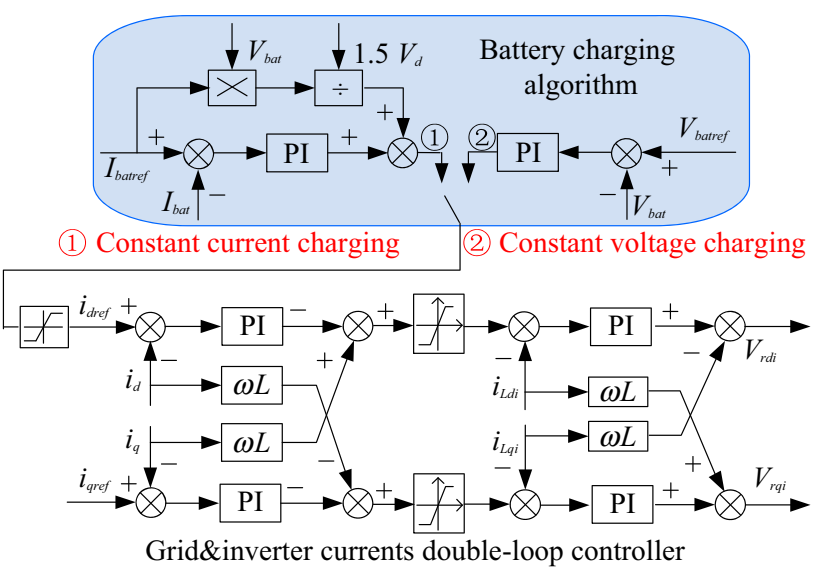

Fig. 4 Controller block of charging in V2G mode

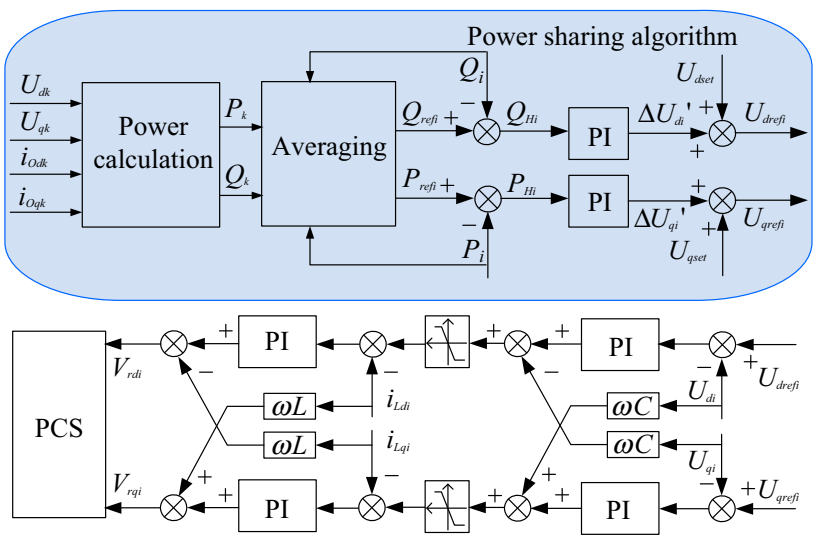

Capacitor voltage\&inverter current double-loop controller

Fig. 5 Control strategy of stand-alone mode

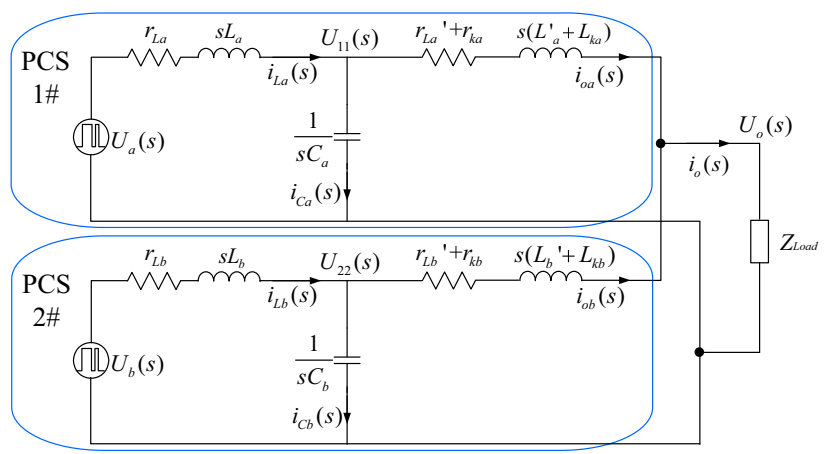

Fig. 6 Equivalent circuit of paralleled PCS in stand-alone mode

controllers are achieved by CAN, including active-reactive power, battery status and control instructions. The module output impedance is highly inductive because of the transformer leakage inductance and inductance on the grid side of LCL filter. Therefore, the active power flow and reactive power flow are mainly influenced by the phase angle and the amplitude of the output voltage respectively. The decoupling control of $\mathrm{d} / \mathrm{q}$-axis voltage reference and active-reactive power error are realized effectively under $d q$ synchronous rotating coordinate. The equivalent circuit of parallel connected PCS in the stand-alone mode is shown in Fig. 6.

\subsection{Seamless transfer mode}

Figure 7 shows the proposed control block diagram for V2G and stand-alone operations of PCS module. When PCS transfers between V2G mode and stand-alone mode, the outer loop simultaneously changes from the grid current control mode for V2G operation to the capacitor voltage control mode for stand-alone operation. The voltage-current double-loop control in the stand-alone mode is a conventional strategy, widely used in three-phase voltage 


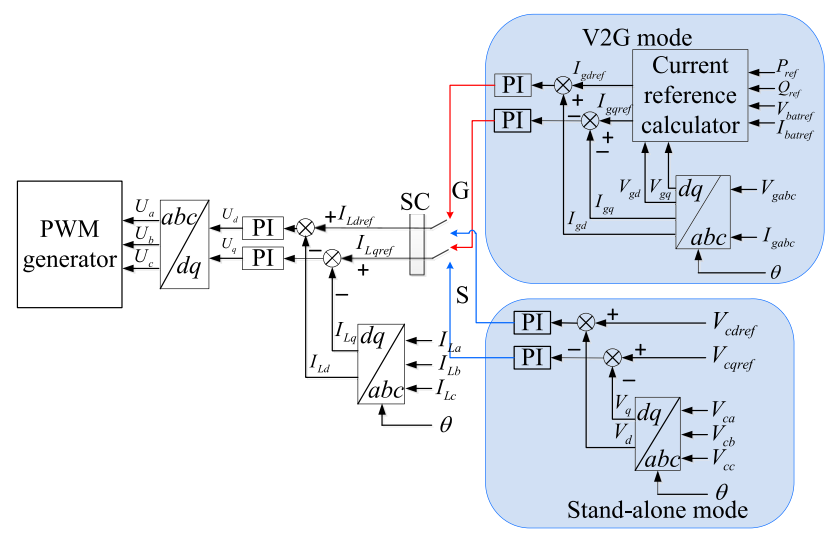

Fig. 7 Novel seamless transfer control strategy

source inverter. The parameter design and stability analysis of current double-loop control in the V2G mode is discussed in $[21,22]$. During the process of transfer, the outer loops track current instruction mutually while the inner loop for inverter current control remains the same. In this case, it can be regarded as change in control instructions rather than change in controllers, the stability in both the stand-alone mode and the $\mathrm{V} 2 \mathrm{G}$ mode guarantees the stable transition period between stand-alone mode and $\mathrm{V} 2 \mathrm{G}$ mode.

A detailed sequence for the seamless transfer from V2G to stand-alone operation is summarized as follows. The process of the seamless transfer from V2G to stand-alone mode is illustrated in Fig. 8.

1) Judge a fault or scheduled maintenance on the grid.

2) Preparing for mode transfer adhere to stand-alone specification.

3) The static transfer switch (STS) is tripped in order to disconnect the PCS from the utility grid.

4) The control switch $S_{c}$ is connected to 'S' from 'G', PCS changes its control from current control mode to voltage control mode.

5) Gradually change voltage references $V_{\text {cdref }}$ and $V_{\text {cqref }}$ to the desired values. The initial value of the $V_{c d r e f}$ and $V_{\text {cqref }}$ is determined by grid voltage $V_{g d}$ and $V_{g q}$, which is calculated from the measured three-phase grid voltages at the transfer point.

In the meanwhile, a detailed sequence for the seamless transfer from stand-alone to V2G operation is summarized as follows. The process of the seamless transfer from standalone to V2G mode is illustrated in Fig. 9.

1) Detect that the grid voltage is within the normal operating range.

2) Preparing for mode transfer adhere to V2G specification.

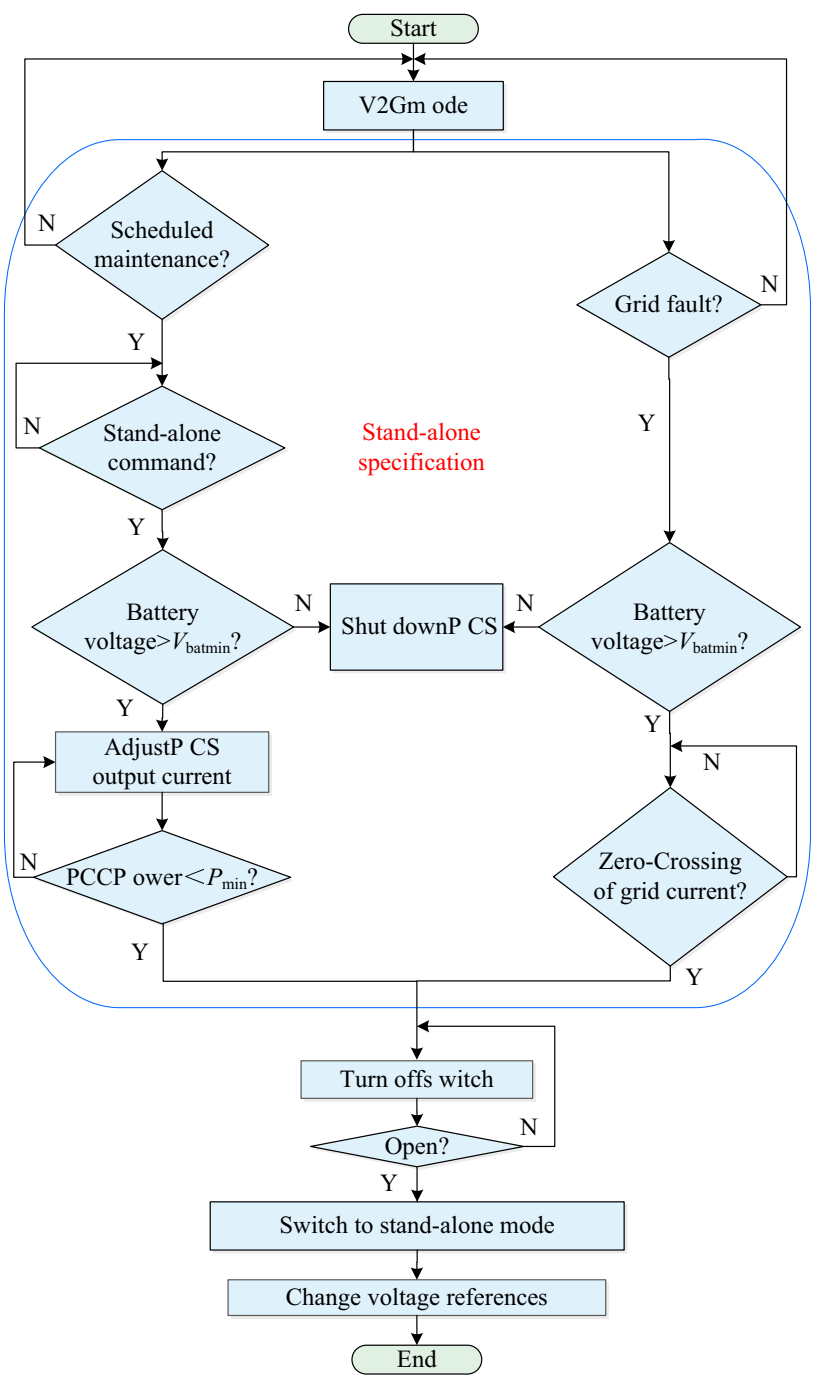

Fig. 8 Transfer sequence from V2G to stand-alone mode

3) When the frequency, phase and magnitude of the PCS output voltage match the grid voltage, the STS is closed. The PCS is connected to the utility grid afterwards.

4) The control switch $S_{c}$ is connected to ' $G$ ' from ' $\mathrm{S}$ ', PCS changes its control from voltage control mode to current control mode.

5) Gradually change the current reference $I_{\text {gdref }}$ and $I_{\text {gqref }}$ to the desired values.

\section{Experimental results}

An experimental device of parallel-connected PCS has been built to verify the proposed control method with the parameters and prototype shown in Table 1 and Fig. 10 respectively. 


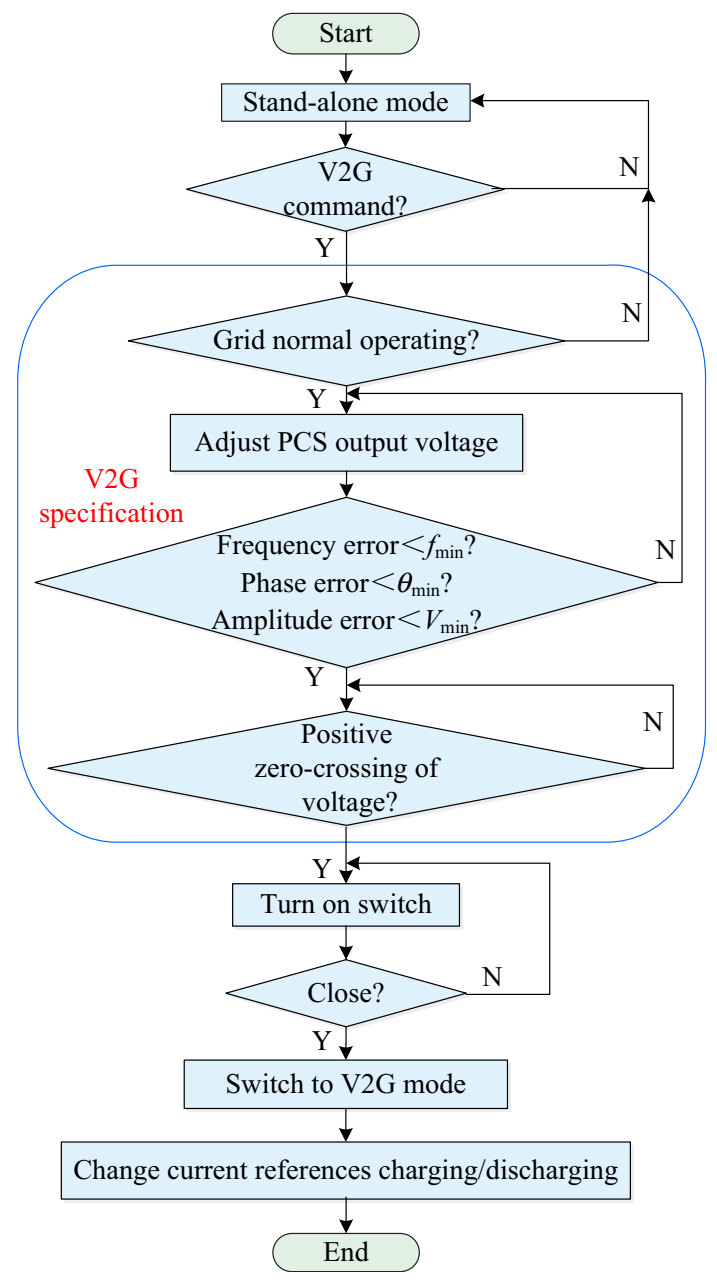

Fig. 9 Transfer sequence from stand-alone to V2G mode

Table 1 Experiment specification of PCS module

\begin{tabular}{lll}
\hline Parameter & Symbol & Value \\
\hline Rated power & $S$ & $500 \mathrm{kVA}$ \\
Grid voltage & $V g$ & $380 \mathrm{~V} / 50 \mathrm{~Hz}$ \\
Switching frequency & $F s$ & $3 \mathrm{kHz}$ \\
$\triangle$-Y Transformer ratio & $N$ & $315: 380$ \\
DC filter inductance & $L_{d c}$ & $0.17 \mathrm{mH}$ \\
DC bus capacitor & $C_{d c}$ & $22 \mathrm{mF}$ \\
Inverter-side inductance & $L_{1} / L_{2}$ & $0.36 \mathrm{mH}$ \\
Grid-side inductance & $L$ & $0.05 \mathrm{mH}$ \\
AC filter capacitor & $C$ & $200 \mu \mathrm{F}$ \\
\hline
\end{tabular}

Figure 11 shows the experimental waveforms of both charging and discharging process in the $\mathrm{V} 2 \mathrm{G}$ mode. The THD of grid-side current fulfills the grid standard, and DC bus voltage ripple is limited.

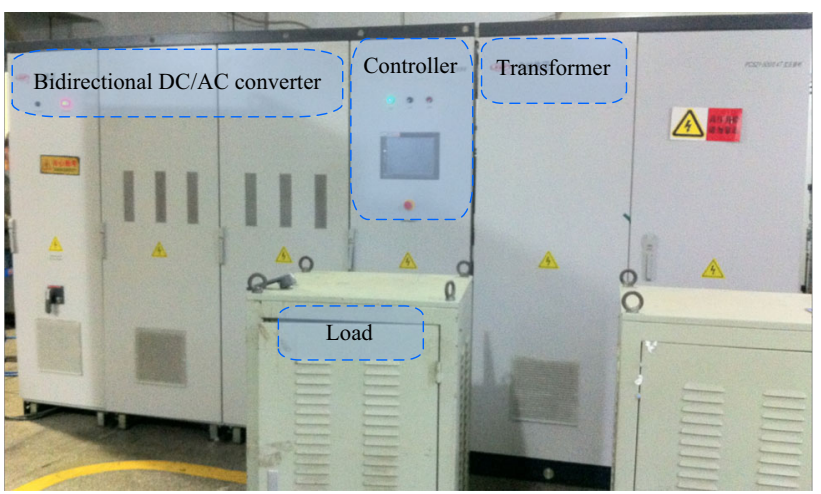

Fig. 10 Experimental device of parallel-connected PCSs

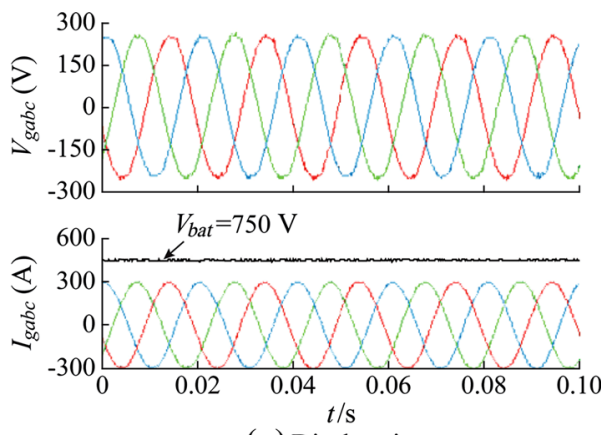

(a) Discharging

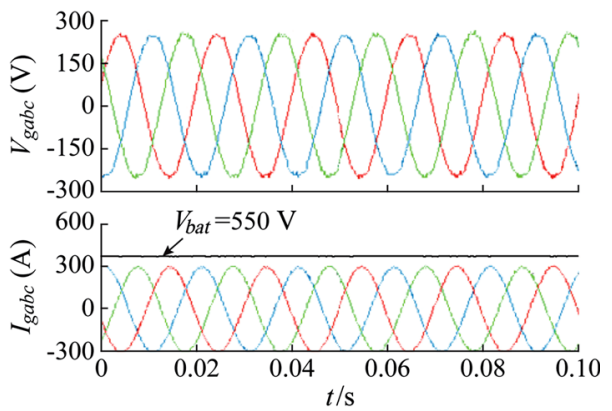

(b) Charging

Fig. 11 Experimental waveforms of charging and discharging process in the V2G mode

Figure 12 shows the experimental waveforms of load current sharing in the stand-alone mode. It is clearly that the steady-state and dynamic performance of parallel connected PCS is excellent during load variation.

Figure 13 shows the experimental waveforms of the seamless transfer process from V2G mode to stand-alone mode. Figure 14 shows the experimental waveforms of the seamless transfer process from stand-alone mode to V2G mode when grid fault occurs. The proposed transfer strategy is capable of providing the critical loads with a stable and seamless sinusoidal voltage during the whole transition period. 

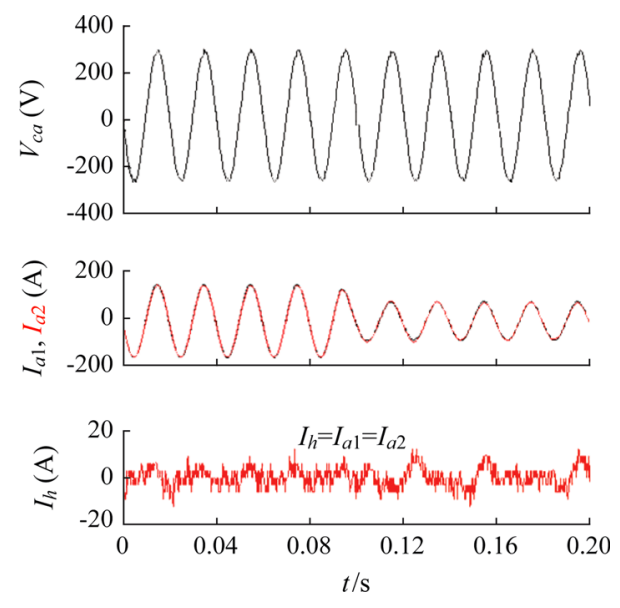

Fig. 12 Experimental waveforms of load sharing in the stand-alone mode
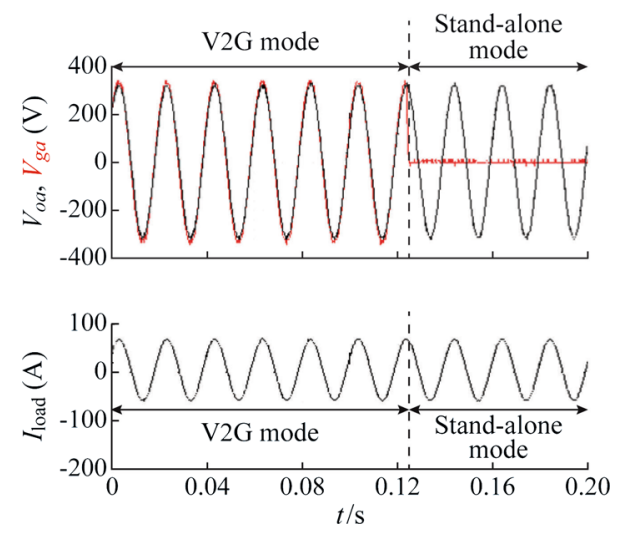

Fig. 13 Experimental waveforms of the proposed control showing a mode transfer from $\mathrm{V} 2 \mathrm{G}$ mode to stand-alone mode

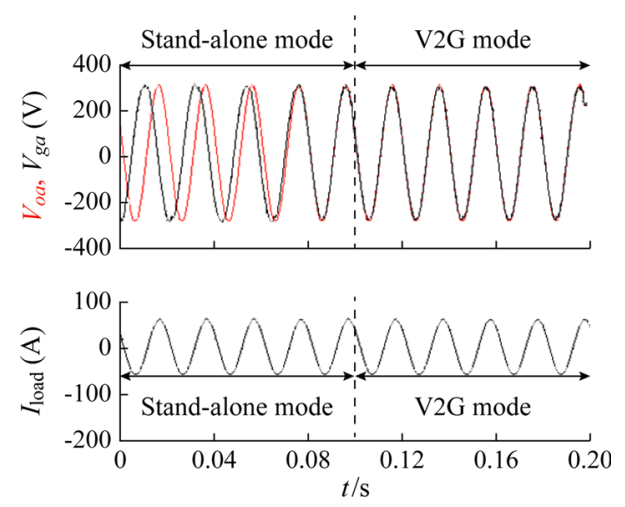

Fig. 14 Experimental waveforms of the proposed control showing a mode transfer from stand-alone mode to $\mathrm{V} 2 \mathrm{G}$ mode

\section{Conclusion}

In this paper, a centralized control strategy for parallel connected PCS in EV Charge-discharge and storage integration station is designed. The PCS infrastructure and operational principles are illustrated, controllers are analyzed in both V2G mode and stand-alone mode. A novel seamless transfer strategy and detailed sequence have been proposed and utilized to achieve better performance between V2G mode and stand-alone mode. The effectiveness of the proposed control strategies have been validated with comprehensive experimental results under various operations.

Acknowledgment This work was supported in part by the National Natural science Foundation of China under Grant 51361130150 and Grant 51477067, in part by the Fundamental Research Funds for the Central Universities under Grant 2014QN219.

Open Access This article is distributed under the terms of the Creative Commons Attribution 4.0 International License (http:// creativecommons.org/licenses/by/4.0/), which permits unrestricted use, distribution, and reproduction in any medium, provided you give appropriate credit to the original author(s) and the source, provide a link to the Creative Commons license, and indicate if changes were made.

\section{References}

[1] Luo ZW, Song YH, Hu ZC et al (2011) Forecasting charging load of plug-in electric vehicles in China. In: Proceedings of the 2011 IEEE power and energy society general meeting, San Diego, CA, USA, 24-29 Jul 2011, 8 pp

[2] Madawala UK, Thrimawithana DJ (2011) A bidirectional inductive power interface for electric vehicles in V2G systems. IEEE Trans Ind Electron 58(10):4789-4796

[3] Khayyam H, Ranjbarzadeh H, Marano V (2012) Intelligent control of vehicle to grid power. J Power Sources 201:1-9

[4] Chen CS, Duan SX, Cai T et al (2011) Optimal allocation and economic analysis of energy storage system in microgrids. IEEE Trans Power Electron 26(10):2762-2773

[5] Ortega-Vazquez MA, Bouffard F, Silva V (2012) Electric vehicle aggregator/system operator coordination for charging scheduling and services procurement. IEEE Trans Power Syst 28(2):1806-1815

[6] Zheng Y, Dong ZY, Xu Y et al (2014) Electric vehicle battery charging/swap stations in distribution systems: comparison study and optimal planning. IEEE Trans Power Syst 29(1): 221-229

[7] Boulanger AG, Chu AC, Maxx S et al (2011) Vehicle electrification: status and issues. Proc IEEE 99(6):1116-1138

[8] Gouveia C, Leal Moreira C, Peças Lopes JA et al (2013) Microgrid service restoration: the role of plugged-in electric vehicles. IEEE Ind Electron Mag 7(4):26-41

[9] Lopez MA, Martin S, Aguado JA et al. (2011) Optimal microgrid operation with electric vehicles. In: Proceedings of the 2nd IEEE PES international conference and exhibition on innovative smart grid technologies (ISGT Europe'11), Manchester, UK, 5-7 Dec 2011, 8 pp

[10] Chen CS, Duan SX (2014) Optimal integration of plug-in hybrid electric vehicles in microgrids. IEEE Trans Ind Inform 10(3):1917-1926

[11] Lee YJ, Emadi A (2014) Integrated bi-directional AC/DC and DC/DC converter for plug-in hybrid electric vehicle conversion. 
In: Proceedings of the 2007 IEEE vehicle power and propulsion conference (VPPC'07), Arlington, TX, USA, 9-12 Sept 2007, pp 215-222

[12] Onar O, Kobayashi J, Khaligh A (2011) A multi-level grid interactive bi-directional AC/DC-DC/AC converter and a hybrid battery/ultra-capacitor energy storage system with integrated magnetics for plug-in hybrid electric vehicles. In: Proceedings of the 26th IEEE annual applied power electronics conference and exposition (APEC'11), Fort Worth, TX, USA, 6-11 Mar 2011, pp 829-835

[13] Zhou XH, Lukic S, Bhattacharya S et al (2009) Design and control of grid-connected converter in bi-directional battery charger for plug-in hybrid electric vehicle application. In: Proceedings of the 2009 IEEE vehicle power and propulsion conference (VPPC'09), Dearborn, MI, USA, 7-10 Sept 2009, pp 1716-1721

[14] Tan KT, Peng XY, So PL et al (2012) Centralized control for parallel operation of distributed generation inverters in microgrids. IEEE Trans Smart Grid 3(4):1977-1987

[15] Guerrero JM, Hang LJ, Uceda J (2008) Control of distributed uninterruptible power supply systems. IEEE Trans Ind Electron 55(8):2845-2859

[16] Liu BY, Duan SX, Cai T (2011) Photovoltaic DC-buildingmodule-based BIPV system: concept and design considerations. IEEE Trans Power Electron 26(5):1418-1429

[17] Tran TV, Chun TW, Lee HH et al (2014) PLL-based seamless transfer control between grid-connected and islanding modes in gridconnected inverters. IEEE Trans Power Electron 29(10):5218-5228

[18] Guo ZQ, Sha DS, Liao XZ (2014) Voltage magnitude and frequency control of three-phase voltage source inverter for seamless transfer. IET Power Electron 7(1):200-208

[19] Liu Z, Liu JJ (2014) Indirect current control based seamless transfer of three-phase inverter in distributed generation. IEEE Trans Power Electron 29(7):3368-3383

[20] Ochs DS, Mirafzal B, Sotoodeh P (2014) A method of seamless transitions between grid-tied and stand-alone modes of operation for utility-interactive three-phase inverters. IEEE Trans Ind Appl 50(3):1934-1941

[21] Azani H, Massoud A, Benbrahim L et al (2014) An LCL filterbased grid-interfaced three-phase voltage source inverter: performance evaluation and stability analysis. In: Proceedings of the 7th IET international conference on power electronics, machines and drives (PEMD'14), Manchester, UK, 8-10 Apr 2014, $6 \mathrm{pp}$

[22] Hu XF, Wei Z, Chen YH et al (2012) A control strategy for gridconnected inverters with LCL filters. Proc CSEE 32(27):142-148 (in Chinese)
Jiuqing CAI received the B.S. degree in electrical engineering and automation from Huazhong University of Science and Technology, Wuhan, China in 2011. He is currently working for Ph.D. degree in School of Electrical and Electronics Engineering, Huazhong University of Science and Technology. His research interests include power conditioning system, UPS and renewable energy applications.

Changsong CHEN received the Ph.D. degrees in electrical engineering from Huazhong University of Science and Technology, Wuhan, China, in 2011. He was a Postdoctoral Research Fellow with the Department of Control Science and Engineering, Huazhong University of Science and Technology, from 2011 to 2013. He is currently a faculty member in the School of Electrical and Electronics Engineering, Huazhong University of Science and Technology. His current research interests include renewable energy applications, microgrid and power electronics applied to electric vehicles.

Peng LIU received the B.S. degree in electrical engineering from Huazhong University of Science and Technology, Wuhan, China in 2013.He is currently working for Ph.D. degree in School of Electrical and Electronics Engineering, Huazhong University of Science and Technology. His research interests include power conditioning system, UPS and modular DC-DC applications.

Shanxu DUAN received the B.Eng., M. Eng., and Ph.D. degrees in electrical engineering from Huazhong University of Science and Technology, Wuhan, China, in 1991, 1994, and 1999, respectively. Since 1991, he has been a Faculty Member in the College of Electrical and Electronics Engineering, Huazhong University of Science and Technology, where he is currently a Professor. His research interests include stabilization, nonlinear control with application to power electronic circuits and systems, fully digitalized control techniques for power electronics apparatus and systems, and optimal control theory and corresponding application techniques for high-frequency pulsewidth-modulation power converters. Dr. Duan is a Senior Member of the Chinese Society of Electrical Engineering and a Council Member of the Chinese Power Electronics Society. He was selected as one of the New Century Excellent Talents by the Ministry of Education of China in 2007. He was also the recipient of the honor of "Delta Scholar" in 2009. 